\title{
Transgredir o gênero: políticas da escritura na literatura hispano-americana atual
} Ana Cecilia Olmos*

\begin{abstract}
Alertas, desafiantes ou perplexos, os escritores oscilam entre essas atitudes na hora de definir o cenário atual da literatura da América Latina. Não é raro que em seus ensaios apelem à imagem da literatura como uma arte ameaçada de dissolução pelas condições que impõem a lógica do mercado e o avanço da tecnologia e suas novas linguagens. Ante a iminência do perigo, a definição do exercício literário como um trabalho de risco não demora em chegar. Roberto Bolaño usa esses termos quando afirma que uma escritura de qualidade "é o que sempre foi: saber enfiar a cabeça na escuridão, pular para o vazio, saber que a literatura é basicamente um ofício perigoso" (2008, p. 36) (tradução minha). Não é menos enfático Jorge Volpi ao se referir à literatura como uma arte sitiada pela cultura do entretenimento que a reduz ao "maneirismo do policialesco, do negro, do fantástico e do folhetinesco" (2008, p. 36) (tradução minha). Para resistir ao cerco, Volpi não duvida em convocar autores e leitores para defender a complexidade, a profundidade e o risco de escrituras que desafiem as convenções. Mais atenuada, porém não menos instigadora, é a posição de Sergio Chejfec que se inclina pelas escrituras que se aventuram na complexidade formal e exibem o artifício literário; no entanto, ele arrisca a pergunta acerca da vigência e, sobretudo, da eficácia desse gesto moderno na literatura de hoje. Sem respostas definitivas, Chejfec assinala que "boa parte do que entendemos como literatura se transformou em algo obscuro e imprevisível, que repudia as interpretações gerais e tende a construir sentidos parciais a partir de unidades fragmentárias" (2005, p. 135) (tradução minha).

Se, como afirmam esses autores, a literatura atual corre o risco de se esclerosar na repetição de fórmulas fixas ou se dispersar numa multiplicidade estética inapreensível, talvez seja interessante colocar a pergunta sobre a existência e a persistência de políticas de escritura que, nos dias de hoje, trabalham nas margens do institucionalizado como forma de resistir à sedução fácil das convenções. Noutras palavras, se restam indícios do literário entendido em termos de modernidade artística, talvez se inscrevam em escrituras que impulsionam a literatura em direção de uma
\end{abstract}

* Professora de Literatura Hispano-Americana na Universidade de São Paulo (USP) e pesquisadora do CNPq. E-mail: anaolmos@usp.br 
deriva estética que desestabiliza as convenções, não para propor outras formas que acabem igualmente esclerosadas na proteção de seus limites, senão para levar a literatura para além do limite, empurrá-la permanentemente para o abismo que se abre quando se renuncia à tranquilidade das linguagens ordenadas e as certezas de seus fundamentos.

Nessa linha de pensamento, quero comentar algumas escrituras que trabalham nas fronteiras dos gêneros literários, exploram seus limites, os transgridem e, por deslocamento, inversão ou deformação, alteram os pressupostos do gênero. Por certo, esta questão não comporta nenhuma novidade, sabemos que a arte moderna fez da exploração do limite a condição de possibilidade da literatura. Não se trata, portanto, de reativar a anacrônica contenda entre antigos e modernos; como explica Alberto Giordano, desde Mallarmé, a literatura sabe que só pode ser literatura na medida em que se destrói a si mesma e se oferece como promessa do que ainda não é (Giordano, 2010, p. 11). O que me interessa pensar são as políticas que assumem algumas escrituras ao socavar, desde seu interior, a convenção do gênero, traçando um movimento de transgressão que abre a passagem da literatura para o impensado e o ilimitado. Noutras palavras, trata-se de refletir sobre políticas de escrituras nas quais, como afirma Foucault, a interrogação acerca do limite substitui a busca da totalidade e onde o gesto da transgressão substitui o movimento das contradições (Foucault, 1964, p. 248).

Os romances do mexicano Mario Bellatin, que se deslocam com irreverência entre a autobiografia e a ficção, e os livros raros que organiza a chilena Diamela Eltit, modelando com peculiaridade a matéria do testemunho, podem ser bons exemplos de políticas de escritura contemporâneas que arriscam formas estéticas críticas ao encerramento da literatura na transparência natural dos limites de gênero. Como explica Foucault, a transgressão é um gesto obstinado que concerne ao limite, isto é, limite e transgressão dependem um do outro; nesse sentido, quando se transgride um limite, ele não é simplesmente apagado, paradoxalmente, ele torna-se visível evidenciando, assim, sua verdade positiva no movimento da perda. Poderíamos dizer, portanto, que, ao transgredir os limites do gênero, estas escrituras não os ignoram apenas, pelo contrário, os tornam visíveis para poder mostrar sua verdade positiva no próprio processo de negação; noutros termos, estas formas críticas desnaturalizam o gênero para afirmar a singularidade da literatura ou, em palavras de Giordano, "a existência sem ser do literário". 


\section{Limites da autobiografia}

$\mathrm{Na}$ contramão das épicas triviais do eu que permeiam muitos relatos de vida que respondem às demandas do mercado, alguns romances de Mario Bellatin transitam, com significativa singularidade, pelos limites do gênero autobiográfico. Títulos como Lecciones para una liebre muerta (2005a), Underwood portátil (2005b) e El gran vidrio: tres autobiografías (2007) podem ser pensados como narrativas que se interrogam acerca das diferentes formas que podem assumir as instâncias de mediação quando se exploram os vínculos entre vida e escritura. De acentuado caráter experimental, essas narrativas submetem o relato de vida a um jogo alucinado de mediações e fazem desvariar o gênero, colocando em evidência o núcleo fictício que se esconde em toda autobiografia e afirmando, em última instância, que a autobiografia só pode assumir a forma de sua impossibilidade.

Sabemos que as condições básicas da autobiografia dizem respeito à identificação do autor com o narrador, a uma narração que desdobra a sequência temporal de uma vida e ao voto de sinceridade que garante a verdade do relatado. No entanto, como diz Jean Starobinski (2008, p. 77-84), essas condições não definem uma forma própria do gênero autobiográfico. Segundo este autor, não se pode reconhecer um modelo para a autobiografia senão apenas estilos particulares, isto é, o modo peculiar a partir do qual cada escritor cumpre com essas condições gerais que a tornam possível. Ao definir a autobiografia nesses termos, como um modo singular de enunciação, Starobinski destaca a relevância que ganha esse eu que se dispõe a relatar com autenticidade uma experiência de vida que se recorta no passado. Certamente, a singularidade dessa enunciação, que se identifica com a noção de estilo, interfere na verdade da experiência que se relata dado que essa verdade só pode ser evocada desde o presente a partir do qual o sujeito lhe atribui um sentido e lhe impõe uma forma. Toda escritura autobiográfica, portanto, supõe uma percepção mediada da experiência que se deseja relatar, supõe uma interpretação que se realiza desde o presente da enunciação e, nesse sentido, o eu da escritura autobiográfica é indiscernível do $e u$ do relato de ficção. É fácil concluir, explica Starobinski, que sob a forma da narração e, para além do voto de sinceridade, o conteúdo da autobiografia pode se deslizar para a ficção e nada pode deter essa passagem de um plano a outro.

Em Lecciones para una liebre muerta, Bellatin explicita e exacerba esse deslizamento da autobiografia para a ficção como estratégia narrativa. $\mathrm{O}$ livro desdobra uma série de histórias que se desenvolvem de forma alter- 
nada em 243 fragmentos numerados. A história do poeta cego, a do tradutor, a da irmã do tradutor e os gêmeos deformes, a história de Macaca, a história do escritor, a do fotógrafo cego, a de Margo Glanz e os dublês de autores, todas essas histórias configuram uma narrativa que exige do leitor um jogo de contraponto entre os fragmentos para a construção de um sentido. Poderíamos dizer que todas essas histórias que segmentam o romance são ficções, isto é, relatos autênticos produzidos a partir de uma referência imaginária, no entanto, em vários momentos, o universo fictício dessas histórias se desloca e toca a margem do autobiográfico. Algumas histórias colocam em evidência dados e cenas que remetem à história pessoal do autor, que aproximam a voz narrativa do nome do autor e, ainda, que se projetam na escritura como singularidade estilística. Refiro-me à falta do braço que causara a talidomida e ao uso de próteses substitutivas que marcaram a vida de Bellatin e que podem ser reconhecidas no retorno do "raro" como tópico de produtividade ficcional, sobretudo, na configuração das personagens, muitas delas particularizadas pela bizarria de algum atributo. Não obstante, esse traço autobiográfico também pode se apresentar de forma mais evidente numa enunciação subjetiva que prescinde da mediação da personagem. No fragmento 188, o narrador lembra das oficinas onde se fabricavam as próteses que usava na infância:

Quase sempre ficavam nos porões de grandes hospitais. Que visitava com mais frequência, acompanhado de meus pais ou das senhoras que queriam assegurar a preservação de minhas próteses, era um lugar desolado. (Bellatin, 2005a, p. 110) (tradução minha)

Atribuída ou não ao autor Mario Bellatin, essa enunciação se desloca, com marcada ambiguidade, entre a ficção e a autobiografia, desestabilizando tanto o estatuto imaginário do romance como a veracidade da experiência vivida. Inclusive, em outros momentos, essa suposta enunciação autobiográfica que permitiria restabelecer os vínculos entre autor e narrador, evidencia-se ainda mais ao introduzir a condição de escritor de quem narra. No fragmento 22, o narrador confessa:

Nunca saberei quais foram as razões pelas quais, desde a minha infância, esforcei-me para ficar horas em frente a uma máquina de escrever. Em um momento pensei que o prazer viesse do surgimento das palavras no papel. Bastava-me vê-las materializadas. Pensei em tornar-me datilógrafo, encantado com o absurdo que vinha do som das teclas. (id., p. 29) (tradução minha)

Em meio de uma série de histórias imaginárias, esse fragmento mostrase próximo demais de uma enunciação autobiográfica e assume com mais 
conviç̧ão esse caráter quando o reencontramos, exatamente nos mesmos termos, em Underwood portátil, uma espécie de ensaio autobiográfico em que Bellatin apresenta uma história de seus livros.

Embora alguns fragmentos, como o citado acima, sugiram a possibilidade de estar ante uma narração autobiográfica do autor, outros fragmentos colocam em cena a figura do escritor como uma personagem que responde pelo nome de mario bellatin. Essa personagem prepara uma instalação artística que multiplicará a escritora mexicana Margo Glanz numa série de dublês que serão instruídos por ela para responder pela autoria de seus textos. Inserido no universo imaginário do relato, esse projeto artístico visa a destituir a ideia de autor como instância positiva e exterior ao texto, duplicando, no interior da narração, o questionamento das relações entre escritura e vida que propõe o livro como um todo.

Os deslizamentos entre autobiografia e ficção exacerbam-se quando a figura de Mario Bellatin retorna numa personagem que não leva seu nome, mas que escreveu um livro publicado pelo autor. $\mathrm{O}$ narrador do fragmento 219 relata: É possível que nestes dias, tendo as visitas do filósofo travesti como inspiração, o escritor começou a dar forma a um projeto narrativo que virou o livro salão de beleza. (id., p. 124) (tradução minha)

Esse jogo de posições enunciativas transgride as condições de possibilidade do gênero autobiográfico na medida em que desestabiliza as relações de identificação entre autor, narrador e personagem, fragmenta a sequência temporal do relato de vida e prescinde da garantia de veracidade do relatado. Lecciones para una liebre muerta propõe-se como uma textualidade ampliada que expande uma escritura que não se postula como a expressão de um sujeito, senão que desenha um efeito de sujeito no texto (Arfuch, 2002, p. 99). Noutras palavras, a narrativa de Bellatin explora os limites de uma escritura autobiográfica que, ao invés de buscar um lugar central e inalienável para a expressão do sujeito, assume seu descentramento constitutivo e, portanto, a impossibilidade de sentidos últimos e estáveis (Catelli, 2007, p. 16).

Em El gran vidrio, esses princípios se radicalizam e Bellatin oferece um relato autobiográfico que se desdobra em três versões. A história do menino cujo corpo nu é exibido nos banheiros públicos pela sua mãe; a história de um escritor que faz parte de uma comunidade religiosa dirigida por uma sheika que está doente; a história de uma jovem que representa uma dança de marionetes cada vez que sua família vai ser despejada. Construídas a partir de um delicado equilíbrio entre a verdade da experiência e a referência imaginária, essas versões levam o autor a se perguntar:

O que há de verdade e o que há de mentira em cada uma das três 
autobiografias? Para saber é necessário verificar que: há personagens reais envolvidas; um antecedente pessoal que tem a ver com a linhagem fascista; uma secretária doente; a impossibilidade de conformação com uma família normal; a necessidade de apagar todos os vestígios do passado, de difundir uma determinada identidade, baseada principalmente na negação de tempo e espaço que deveriam corresponder; mudar de tradição, nome, história, nacionalidade, religião, são uma espécie de constante (...) Mas não para criar novas instituições e, sim, para que o texto seja revelado em todas as suas possibilidades. (Bellatin, 2007, p. 159-60) (tradução minha)

Poderíamos dizer que essa citação de El gran vidrio explicita a peculiaridade que assume a relação entre autobiografia e ficção em Lecciones para una liebre muerta. Uma relação que não se restringe a deslocar o factual para o imaginário, antes, consiste em trabalhar uma singularidade estilística que, na discrição de um tom que ignora a ênfase, no retorno quase obsessivo dos temas ligados ao raro e o deforme, na reiteração de estruturas narrativas segmentadas, inscreve uma subjetividade que sabe do caráter inacabado e provisório de qualquer relato de vida.

\section{Limites do testemunho}

A escritura de Diamela Eltit também explora zonas intersticiais de enunciação que questionam as certezas de gênero. É o caso do seu livro Puño y letra: juicio oral, publicado em 2005, que se organiza a partir da matriz narrativa do testemunho, porém, dialoga com o universo de suas ficções e ensaios. O livro apresenta a transcrição de partes do processo judicial que se realizou contra Enrique Arancibia Clavel, um agente dos serviços de informação do Estado chileno, que participou no assassinato do general Prats e sua esposa, ocorrido em Buenos Aires em 1974.

Eltit transcreve os seguintes documentos: uma carta de Pinochet dirigida a Prats, com data de 1973; a abertura do julgamento oral na cidade de Buenos Aires no ano 2000; a declaração de uma das testemunhas, Hugo Alberto Zambelli, um dançarino do espetáculo portenho amante de Arancibia Clavel; e as alegações dos advogados da família Prats. Segundo explica Eltit na apresentação do livro, a seleção desses documentos visa a colocar em evidência o que o próprio julgamento oral trouxe à tona, por um lado, a conspiração militar que ordenou o assassinato de Prats e sua esposa, comprometendo as instâncias mais altas do poder político da ditadura chilena e, por outro, os sórdidos vínculos que se estabeleceram entre o mundo do espetáculo e a repressão política naqueles anos. Ainda que 
essa seleção de documentos seja deliberada, o caráter fragmentário de sua transcrição solicita do leitor um trabalho de reconstrução da conspiração e do crime por meio do rastreamento dos indícios que semeiam a carta de Pinochet, a declaração da testemunha e as alegações dos advogados da família querelante.

O testemunho de Eltit, que esteve presente em todo o julgamento, enquadra a transcrição dos documentos orais com dois textos. Na apresentação, a autora explicita os motivos que a levaram a organizar o volume, descreve a cena do julgamento e relata, com singular perspicácia, a história de vida de Arancibia Clavel, traçando um retrato do acusado que se pauta em dados fidedignos, mas não prescinde da conjectura. No final do volume, Eltit incorpora um ensaio, intitulado "1974" que dilata o foco da memória e que, para além da reconstrução da cena judicial de Buenos Aires, propõe a palavra da autora como testemunho de uma habitante de Santiago, a capital chilena, naquele ano de 1974, quando a violência de Estado atingiu sua expressão mais sinistra sob o acionar dos serviços de inteligência clandestinos. Trata-se, portanto, de um testemunho que se organiza não só para não esquecer o crime, fundamento das políticas públicas da memória, senão também para indagar o aniquilamento das subjetividades, a repressão dos corpos e a devastação das cidades que levaram adiante os mecanismos repressivos do Estado e a exacerbação da lógica capitalista daqueles anos. Conflitos que mobilizam o universo literário de Eltit, que se tornam visíveis nos enredos dos romances e, ainda, na dilaceração das formas estéticas de seus livros. Com efeito, títulos como Lumpérica (1983), El padre mío (1989) ou Mano de obra (2002) trabalham pela reconstrução de uma memória da ditadura chilena, porém, desde uma posição crítica que evita o encerramento do ato criativo numa militância política programática e, portanto, resiste à clausura da escritura na fixidez dos sentidos.

Em diálogo com esse projeto criativo de marcado caráter experimental, a estrutura fragmentária que assume a matéria testemunhal de Puño y letra: juicio oral socava os pressupostos romântico-realistas que, com frequência, adotam os testemunhos. Como explica Beatriz Sarlo, alguns testemunhos das últimas ditaduras militares do Cone Sul da América Latina podem ser pensados como narrativas românticas na medida em que se centram na expressão, muitas vezes efusiva e sentimental, da primeira pessoa, evidenciando a confiança de quem narra na mediação da linguagem como instância de representação de uma subjetividade. Por outro lado, o pressuposto realista que sustenta esses testemunhos pode ser reconhecido na ideia de que a acumulação de peripécias produz o sa- 
ber buscado e que esse saber poderia ter uma significação geral (Sarlo, 2005, p. 74-6). A estrutura fragmentária que organiza o testemunho em Puño y letra: juicio oral desestabiliza esses pressupostos. Eltit testemunha o julgamento oral de Arancibia Clavel e sua voz organiza todo o relato; no entanto, ao transcrever os documentos, essa enunciação abre espaço para outras vozes que a própria cena judicial convoca, deixando que o texto seja permeado por uma mescla de registros linguísticos. O lirismo subjetivo permeia a escrita ensaística dos textos que enquadram a transcrição dos documentos, o discurso jurídico domina nesses últimos e a representação teatral não está ausente no interrogatório de Zambelli, cuja declaração evoca, nas interferências dos diálogos, uma peça do absurdo. Por outra parte, a sequência temporal fragmenta-se na seleção de alguns momentos do julgamento, exatamente aqueles que permitem a Eltit organizar um relato que vai além do julgamento de um crime em particular para indagar a devastação social que impôs aquela experiência histórica. Essa estrutura descentrada e descontínua, que evidencia os procedimentos de construção do texto, aproxima o testemunho do projeto criativo de Eltit na medida em que desdobra uma escritura que abre ao indeterminado as possibilidades do sentido e resiste à clausura da significação na moral humanista dos discursos ideologizados. Por certo, exibir o movimento de uma palavra que abre ao indeterminado as possibilidades do sentido, não impede que Eltit diga uma verdade, a verdade de sua posição ética e política ante o crime de Estado.

Não obstante, a teatralidade da cena jurídica e o tempo transcorrido entre o assassinato e o julgamento impõem uma pergunta que permeia todo o texto: "Faz sentido?". Eltit formula para si mesma a pergunta no primeiro dia do julgamento e a faz ecoar em todo seu testemunho. Na última parte do livro, cujo título é "Trans-versalmente", ensaia uma resposta, oblíqua, que poderíamos resumir da seguinte maneira: o testemunho do julgamento de Arancibia Clavel ganha sentido se trabalha a favor de uma memória crítica do acontecido que permita indagar de que forma a depredação desse crime de Estado se projetou noutros sujeitos contemporâneos a ele. Noutras palavras, 1974, o ano do assassinato, exige também o testemunho dos outros, dos habitantes de Santiago, dessa comunidade anônima, sitiada e silenciada na qual Eltit se reconhece. No texto que encerra o testemunho, ela diz:

Aprendemos a nos destruir. Um grande contingente de errantes na cidade, passando pelos espaços públicos, contornando os informantes, transvestindo-nos em nada, lutando pela sobrevivência, procurando desesperadamente transformarmo-nos em seres cinzentos e 
insignificantes à custa de consumirmo-nos, em um pouco de nós mesmos: raiva e tristeza. (Eltit, 2005, p. 188) (tradução minha)

Nessas últimas páginas, o testemunho expande-se para além da cena judicial e Eltit enuncia desde um lugar coletivo e anônimo; para sermos mais precisos, enuncia desde um lugar à margem das políticas públicas que administram a memória da ditadura chilena porque, como ela explica, os imaginários sociais e seus componentes raciais e de classe segmentaram a cidadania em vítimas de primeira e de segunda. Nesse sentido, o testemunho do julgamento de Arancibia Clavel dá conta da extrema violência que atingiu a política repressiva da ditadura do Chile e aspira a restituir os vínculos da comunidade, porém, ciente das relações de desigualdade que a permeiam.

Não obstante, paralelamente a esse movimento inclusivo da voz, abrem-se parênteses, nos quais a enunciação se individualiza e põe em evidência a impossibilidade de fazer do testemunho um processo de luto que repare a subjetividade dilacerada. No parêntese que se abre logo após o parágrafo acima citado, Eltit acrescenta: (Em uma parte que não para. Meu corpo crônico a partir desse ano e não tem mais cura. Carrego a cicatriz que encobre a ferida mortal que atravessou minha alma de forma irreversivel. (2005, p. 189) (tradução minha)

A singularidade que assume a forma do testemunho de Eltit potencia o radicalismo crítico do gênero porque resiste a um uso instrumental da palavra que enclausure o sentido nos estereótipos expressivos da denúncia ideológica, a pedagogia redentora ou a confissão reparadora. Noutras palavras, quando explora os limites do gênero testemunhal, Eltit persevera numa escritura que, como ela explica, "se estabelece justo no centro traumático em que convergem dor e crueldade, para, deste modo, exercer uma análise desconstrutiva" (Eltit, 2008, p. 224) (tradução minha).

As políticas de escritura que assumem os projetos criativos de Bellatin e de Eltit inquietam as taxonomias dos gêneros ao apelar a procedimentos discursivos que desconfiam da representação da subjetividade e da verdade e, portanto, não se encerram nas certezas de suas expressões. Nesse sentido, podem explorar os limites da autobiografia ou do testemunho num movimento de transgressão que, como explica Derrida (1980), evidencia uma relação de participação na convenção do gênero, mas não um pertencimento a ele. Essas políticas de escritura interrogam o gênero, exploram seus limites e, para usar a expressão de Bolaño, saltam ao vazio, sem admitir uma resposta. 


\section{Referências bibliográficas}

ARFUCH, Leonor (2002). El espacio biográfico: dilemas de la subjetividad contemporánea. Buenos Aires: FCE.

BARTHES, Roland (2006). El grado cero de la escritura: Buenos Aires - siglo XXI. BELLATIN, Mario (2005a). Lecciones para una liebre muerta. Barcelona: Anagrama. Alfaguara.

(2005b). “Underwood portátil modelo 1915”. In: Obra reunida. México:

(2007). El gran vidrio: tres autobiografías. Barcelona: Anagrama.

BOLAÑO, Roberto (2008). "Derivas de la pesada". In: Entre paréntesis: ensayos, artículos y discursos (1998-2003). Barcelona: Anagrama. p. 23-39.

CATELLI, Nora (2007). En la era de la intimidad. Rosario: Beatriz Viterbo.

CHEJFEC, Sergio (2005). "Breves opiniones sobre relatos con imágenes". In: El punto vacilant: literatura, ideas y mundo privado. Buenos Aires: Norma Editorial.

DERRIDA, Jacques (1980). "La loi du genre". Critical inquiry. n. 7, p. 176-201. ELTIT, Diamela (1983). Lumprécia. Santiago: Ed. del Ornitorrinco. (1989). El padre mío. Santiago: Francisco Zegers.

(2004). Mano de obra: tres novelas. México: FCE.

(2005). Puño y letra: juicio oral. Santiago: Seix Barral.

(2008). "Enunciar, anunciar, denunciar: el arte como archivo". In: Signos vitales: escritos sobre literatura, arte y política. Santiago: Ediciones Universidad Diego Portales, p.222-5.

FOUCAULT, Michel (1964). "Préface à la transgression". In: Dits et écrits. Paris: Gallimard. v. 3, p. 233-61.

GIORDANO, Alberto (Org.) (2010). “Presentación”. Los límites de la literatura. Rosario: Centro de Estudios de Literatura Argentina. p. 5-16.

SARLO, Beatriz (2005). Tiempo pasado: cultura de la memoria y giro subjetivo. Una discusión. Buenos Aires: Siglo XXI.

STAROBINSKI, Jean (2008). “El progreso del intérprete”. In: La relación crítica. Buenos Aires: Nueva Visión. p. 77-84.

VOLPI, Jorge (2008). “De parásitos, mutaciones y plagas”. In: Mentiras contagiosas. Madrid: Páginas de Espuma. p. 23-37.

Recebido em maio de 2011.

Aprovado em julho de 2011. 


\section{resumolabstract}

\section{Transgredir o gênero: políticas da escritura na literatura hispano-america- na atual}

Ana Cecilia Olmos

Esse artigo propõe uma reflexão sobre políticas de escritura da literatura hispanoamericana atual que trabalham nas margens das formas estéticas institucionalizadas, socavando as convenções do gênero literário. Para tanto, analisamos os romances de Mario Bellatin, que se deslocam com irreverência entre a autobiografia e a ficção, e os livros raros que organiza Diamela Eltit, nos quais modela a matéria do testemunho em sintonia com seu universo ficcional. A partir da noção foucaultiana de transgressão, abordamos essas formas estéticas como políticas de escritura que resistem ao encerramento da palavra literária na transparência natural dos limites de gênero.

Palavras-chave: gênero literário, transgressão, Mario Bellatin, Diamela Eltit, autobiografia, testemunho

\section{Genre transgression: writing policies in current Hispanic American literature}

\section{Ana Cecilia Olmos}

This article proposes reflection on the writing policies in current Hispanic American literature that work on the borderline of institutionalized aesthetic forms, which undermines the tradition of the literary genre. To do so, we analyze Mario Bellatin's novels, which deviate from autobiography to fiction in an irreverent way, and the rare books organized by Diamela Eltit, in which she shapes the matter of testimonial in tune with her fictional universe. With the Foucaultian notion of transgression, we approach these aesthetic forms as writing policies that resist the confinement of the literary word in the natural transparency of genre limits.

Key words: literary genre, transgression, Mario Bellatin, Diamela Eltit, autobiography, testimonial

Ana Cecilia Olmos - "Transgredir o gênero: políticas da escritura na literatura hispanoamericana atual". Estudos de Literatura Brasileira Contemporânea, n. 38. Brasília, julhodezembro de 2011, p. 11-21. 